\title{
Effectiveness of the Accelerated Learning Programme on Secondary Level Students
}

\author{
Prachi Sathe $^{1^{*}}$ and Sunita Magre ${ }^{2}$ \\ ${ }^{1}$ Research Scholar, ${ }^{2}$ Research Guide \\ Department of Education, University of Mumbai University of Mumbai, India \\ "Corresponding author: prachisathe22@gmail.com
}

Received: 24-05-2021

Revised: 22-07-2021

Accepted: 13-08-2021

\begin{abstract}
The Free and Compulsory education Act 2009 was first enacted on August 29, 2009 after India gained independence. The implementation of this law started from April 1, 2010. This law created a different awareness about education in the country. Section 16 of the Act, Chapter 4, provides that a student should not be kept in a class for more than one year, as well as special attention on 'continuous comprehensive evaluation' and 'Remedial teaching'. However, this section was misinterpreted and used wrongly. The aim behind this section was to make students capable to achieve the competencies as per the standards in the same academic year with the help of remedial teaching methods. As a result, it has adversely affected the basic learning abilities of the students entering class 9 to 8 . Students in class 9 remained raw in the basic abilities. It causes the poor academic performance and increased the drop out rate at the secondary level. As a measure of this, the School Department of the Government of Maharashtra had adopted the paradigm of ' Accelerated Learning Education ' for the development of basic learning abilities for students in class 9. This paradigm was implemented on an experimental basis in Aarey Colony School. Researcher has come to the conclusion that the study of the effectiveness of this paradigm helped to strengthen the basic learning abilities of the students.
\end{abstract}

Keywords: Effectiveness, Accelerated Learning, secondary level students

On August $15^{\text {th }}, 1947$, India attained independence. After 'independence', India adopted a democratic state system. A separate 'constitution' was created to govern the state of an independent India. Constituent Assembly was formed to constitute a constitution. The members of this meeting drafted the Constitution of India from the ideological ideology. Dr. Babasaheb Ambedkar has contributed significantly to this production. On December 13, 1946, Mt. Pandit Jawaharlal Nehru proposed the goals and objectives of the constitution-drafting (Discussion in the Constituent Assembly, Part $1-13 / 12 / 1946)$. According to these goals, the Constituent Assembly started the creation of the 'Constitution'. The constitution, along with all other elements, has essentially laid out the rights and duties of human beings. In Article
21 of the Constitution of India, Part 21 of the Constitution states that "the State shall provide education to children from six years to fourteen years, as determined by law". Then in 2002, the $86^{\text {th }}$ Constitution was amended. This amendment includes the clause ' $A$ '. Accordingly, 'education' was stated as a fundamental right. On August 27, 2009, the 'Children's Free and Compulsory Education Act' Act came into being. The enforcement of this law began on April 1, 2010 (Gazette of India - Part-2 Vol1). With the introduction of the Right of Children to Free and Compulsory Education Act, 2009, a different awareness was raised in the country.

How to cite this article: Sathe, P. and Magre, S. (2021). Effectiveness of the Accelerated Learning Program on Secondary Level Students. Educational Quest: An Int. J. Edu. Appl. Soc. Sci., 12(2): 101-105.

Source of Support: None; Conflict of Interest: None 
The features of this law are as follows:

$\square$ Free but compulsory education for children aged 6 to 14 .

Access by age.

No proof of age / documentation is compulsory.

Child-centered education.

Efforts for the overall development of the child.

Competent courses.

$\square$ Four components Principal, teachers, parents and society are included in the law room.

$\checkmark$ Look at the development of each child.

Special accommodations for children in need.

$\square$ Prevention of physical and mental punishment.

$\square$ Don't keep a child in a class for more than a year (To that end, pay close attention to each year's eligibility courses).

$\square$ A consistent and comprehensive evaluation method.

Evaluation of educational system.

Thus, according to the provisions of this Act, 'efforts to create an educational environment began. The law came into being. Manuals for implementation were created. Efforts were made to create an educational environment through teacher training in Maharashtra. But unfortunately, the following two section were massively misinterpreted by society well the concern people.

'No child admitted in a school shall be held back in any class or expelled from school till the completion of elementary education' (The Gazette of India - Part II - Section I - 26 th $^{\text {th }}$ August, 2009 - effective date $1^{\text {st }}$ April, 2010).

'Provided that where a child is directly admitted in a class appropriate to his or her age, then, he or she shall, in order to be at par with others, have a right to receive special training, in such manner and within such time limits, as may be prescribed' (The Gazette of India - Part II - Section I - 26 ${ }^{\text {th }}$ August, 2009 - effective date $1^{\text {st }}$ April, 2010).

According to these clauses, all the abilities required in a class are to be fulfilled in that same class in same year. According to the second clause, after taking admission as per the age the syllabus of the previous classes should be completed according to the remedial teaching method. But the spirit behind it was unable to reach up to the schools. However, the students were taken to the upper class without actually measuring their abilities. As a measure of this, the School Department of the Government of Maharashtra had adopted the paradigm of Accelerated Learning Education' for the development of basic learning abilities for students in class 9.

Need of the research: For the first time in the post-independence era, a detailed law on quality primary education came into existence. Despite this, the picture shows that the condition of primary education is deteriorating day by day. Attempts were made at the national / state level to check the effectiveness of implementation of the provisions of the law. Some NGOs also conducted such assessments.

The National Educational Research and Training Council, Delhi (NCERT) conducted a national level examination for students in Government and Government Aided Schools for Classes $3^{\text {rd }}, 5^{\text {th }}$ and $8^{\text {th }}$ on November 13,2017 . The results of this survey are illustrated in the following table (NAS 2017 National Achievement Survey - 2017 Maharashtra State Learning Report).

Table 1: Average Achievement by classes and subjects

\begin{tabular}{llll}
\hline Subject & Std. III & Std.V & Std. VIII \\
\hline Language & $70 \%$ & $61 \%$ & $63 \%$ \\
Mathematics & $65 \%$ & $52 \%$ & $40 \%$ \\
EVS /Science & $69 \%$ & $56 \%$ & $40 \%$ \\
Social Science & NA & NA & $42 \%$ \\
\hline
\end{tabular}

Like the government system, the 'PRATHAM ' NGO conducts annual surveys to look at the educational status of students (ASER). ASER report 2016 states that $37.50 \%$ grade $V$ students cannot read a grade II text book.

A student who is unable to comprehend things at primary level further lags in his Secondary schooling stage. He loses his self-confidence. Since the students' basic learning abilities (concepts) remained raw; he faces hurdles in his studies at secondary level. This results in the students' completing his STD X with lost interest or giving up studies before clearing standard $X$.

Standard I enrolment ratio of students is 9.08 and STD $X$ is 7.7. The disparity observed makes 
it essential at secondary schooling stage and should be put on 'Accelerated Learning'. As a measure of this, the School Department of the Government of Maharashtra had adopted the paradigm of 'Accelerated Learning Education' for the development of basic learning abilities for students in class 9. This paradigm was implemented on an experimental basis in all 1423 government schools in phase 1 . This pattern will help the students gain their confidence once they grasp the basic learning abilities. Such basic learning abilities can be comprehended easily by the students at secondary level by this 'Accelerated Learning' pattern as their grasping power too increases with age. The researcher with the help of selected AREY school teachers and coordinator measure the effectiveness of the 'Accelerated Learning' at secondary level. Researcher was in a role of observer.

Statement of the problem: Effectiveness of the Accelerated Learning Programme on secondary level.

\section{Definition}

Conceptual definition: The paradigm of Accelerated learnings Programme to develop students' basic learning abilities.

Functional definition: The paradigm of Accelerated learnings Programme that help students to develop basic learning abilities in class $9^{\text {th }}$ to learn faster for enjoyable learning in schools affiliated to the state Board of secondary Education.

Secondary level- students of standard $9^{\text {th }}$ and $10^{\text {th }}$.

\section{Aim of the research}

The study of effectiveness of the implementation of Accelerated learning Programme on secondary students.

\section{Objectives of the research}

To Effectively examine the implementation of Accelerated learning Programme.

$\square$ Comparing of progress in pre-test ad post-test of single group students of Government school.

Research question: How the Accelerated learning paradigm will help in developing the basic learning abilities of the students at secondary level.
Scope and limitation: This research is representatively related to one school in the Mumbai division. However, the scope of this research is limited to Government school affiliated to secondary and Higher, Secondary Board Pune. The scope of this research is to see the development of the students in basic learning abilities.

Limitations: The Researcher had some limitations. When looking the effectiveness of the Accelerated learning program to develop the basic learning abilities of the students the factors like regular attendance of students, their home conditions, educational environment have not been addressed while implementing it.

Rational of the study: The researcher before joining the Education Department of Maharashtra has worked as assistant Teacher in Marathi, English medium school as a language teacher in private aided secondary school. She got the opportunity to study the situation of education in Maharashtra, specially at secondary level. After studying the dropout rate in $10^{\text {th }}$ standard researcher come to know the declining situation of secondary level. Specially dropout rate is high in standard $9^{\text {th }}$. If we use the different technique and methods of teaching at secondary level, students can achieve the necessary competencies and can complete the secondary level education.

Research method: The word experiment has a meaning in science. Experiments are performed with the help of physical components. Conclusions are drawn in a highly scientific manner. In that sense, the word experiment is important. Experimental research is a scientific research method. An experiment is an observation made by controlling a particular situation. It is expected to study visual changes in order to establish causal relationships. However, observations are made as to the effect of variations in independent variables on dependent variables and this explains the causal relationship between them. The researcher was working on the planning of the state-level Accelerated learning program initiative. It was decided to do research to see the effectiveness of Accelerated learning program while working at state level. As the researcher lives in Mumbai, Aarey Municipal School in Goregaon (East) was chosen. This initiative was implemented by training the teachers in the school. During this activity, the researcher was in a role 
of observer. With the help of school teachers and coordinator, the researcher observed each stage.

Sampling for the research: Simple random sampling technique was used to select the sample for this research. In simple random sampling, each unit of the population is given an equal chance of being selected There are government as well as government aided Marathi medium schools affiliated with Maharashtra state board. The population of the study is standard $9^{\text {th }}$ students from Marathi medium schools only affiliated with Maharashtra state board. Students selected for the present study were the students of standard $9^{\text {th }}$ of Aery government school. Aarey school had a total of 90 students in class IX in the academic year 2016. Baseline tests were conducted. After evaluation, 39 students got less than 18 marks in English, Science and Mathematics out of those 12 students were selected as the beneficiary students for the research.

Research tool: The teachers of the school implemented the action program according to the technique 'ERAC' chosen by Government of Maharashtra.

$$
\begin{aligned}
& \text { E - Experience } \\
& \text { R-Reflection } \\
& \text { A - Application } \\
& \text { C - Consolidation }
\end{aligned}
$$

Phase 1-15 days- develop basic learning abilities - During those fortnights, emphasis was placed on the teaching and learning of basic concepts in each subject. Students were given E-experience using various teaching aids to clarify this concept. This experience made the use of actual educational teaching aids clear the basic concept to the students.

Phase 2 - 30 days of self-study - Beneficiary students were called to school thirty days before school time. During these thirty-days, the students were motivated for self-study. Reading the next, writing down the important points, reflecting on those points was practiced. After this action of reflection, the students were given the practice of application measures. During this time the teacher was in the role of facilitator.

Phase - 3-15 days- Reinforcement - After 30 days of self- study the teachers did the consolidation of their basic learning abilities.
Analysis of the study: Each student tested based on Unit test 1 and Unit test 2 and evaluated academic performance. We have measured the increment found marks received to students in both tests. Also, students ratio to receive the marks above the $50 \%$ of subject.

English subject: 10\% increment found in Average marks of students received in $1^{\text {st }}$ Unit.

$25 \%$ students received $50 \%$ above marks in $1^{\text {st }}$ Unit which has increases to $63 \%$ in $2^{\text {nd }}$ Unit marks. Students have shown interest in learning language skills with Grammar application, with Interest in Classroom teaching.

Mathematics subject: $\mathbf{1 5 \%}$ increment found in Average marks of students received in $1^{\text {st }}$ Unit. 42\% students received $50 \%$ above marks in $1^{\text {st }}$ Unit which has increases to $83 \%$ in $2^{\text {nd }}$ Unit marks. It has shown affirmative increment in learning of students with understanding the methods of calculations, solving problems with confidence.

Science subject: $\mathbf{1 4 \%}$ increment found in Average marks of students received in $1^{\text {st }}$ Unit.

If $83 \%$ students received $50 \%$ above marks in $1^{\text {st }}$ Unit which has increases to $\mathbf{9 2} \%$ in $2^{\text {nd }}$ Unit marks. It has shown Students are improving in the Basic concepts of the subject and taking Interest in both learning and exam preparation.

\section{DISCUSSION}

The Education Department of the Government of Maharashtra organized Accelerated Learning Programme for class 9 students. If the basic learning abilities of some students remain raw, then they find it difficult to complete the $9^{\text {th }}$ standard course. These students will able to complete their secondary education if they achieve the basic education up to class $8^{\text {th }}$ and it is easy to learn the $9^{\text {th }}$ grade course. In this regard, the basic learning abilities of the students in class $9^{\text {th }}$ was achieved through 'Accelerated Learning Programme'. This had an effect on the progress of the students.

\section{CONCLUSION}

The Education Department of the Government of Maharashtra undertook various initiatives for quality education at the secondary level. Students who remain raw in basic learning abilities from class 5 to 8 cannot compete secondary level 
education. This research proves that these abilities are developed and the students' progress through Accelerated Learning Programme. But instead of introducing Accelerated Learning Programme at the secondary level, if we continue to develop basic learning abilities in every class from class 5 and implement. Accelerated Learning Programme, the result will be much better.

\section{REFERENCES}

Shilpakar Dr. Babasaheb Ambedkar (2016) Constitution of India, Milind publications, Vardha.

Bharat ka Rajpatra - Part II- section 1.

The gazzet of India- part II- section 1: August 2009.

NAS -2017, National achievement survey - Maharashtra state learning report.
Dharmapal Deredaar DnyanVruksha :- 18 vya Shatakatil Bharatiya Shikshan, Bharatiya Shikshan Mandal, Nagpur.

Vinaya Ransingh Prof. Bhagyashri Rahate - Bharatiya Shikshan Padhhatichavikasaani Shaaleyavyavaharache Adhishthan. Mangesh Publications, Nagpur.

Pragatshaikshanik Maharashtra, Government resolution dated: $16^{\text {th }}$ September, 2016.

Accelerated learning program, government resolution dated: $31^{\text {st }}$ December, 2016 
